\section{A comparison of four infrared tympanic thermometers with tympanic membrane temperatures measured by thermocouples}

Purpose: To compare measurements made with four infrared tympanic thermometers (Genius ${ }^{\circledR}$, Thermopit ${ }^{\circledR}$, Quickthermo ${ }^{\circledR}$, and Thermoscan $\left.{ }^{\circledR}\right)$ with those recorded from thermocouples positioned in the contralateral ear.

Methods: Four tympanic thermometers were evaluated in 50 healthy volunteers ( 12 female and 38 male). Temperatures were measured, in random order, at the right tympanic membrane four times and the highest temperature was considered to be the true value measured by each thermometer. The control temperature was measured at the left tympanic membrane using Mon-a-Therm ${ }^{\circledR}$ thermocouples.

Results: The tympanic membrane temperature measured by Genius ${ }^{\circledR}$ correlated best with the Mon-a-therm ${ }^{\circledR}$ measurement $(T M)(r=0.74)$. The tympanic membrane temperatures measured by Thermopit ${ }^{\circledR}$, Quickthermo ${ }^{\circledR}$, and Thermoscan ${ }^{\circledR}$ correlated moderately with $T M(r=0.56,0.63$, and 0.58 , respectively). Mean differences between $T M$ and each temperature $(T C, T T P, T Q$, and $T r S)$ were $-0.3,0.73,0.42$, and $-0.3^{\circ} \mathrm{C}$, respectively. Likewise standard deviations were 0.33 , $0.37,0.35$, and 0.35 .

\section{Key words}

EQUIPMENT: thermometers; thermocouples;

TEMPERATURE: core temperature, measurement, tympanic membrane temperature.

From the Department of Anaesthesia, Yamanashi Medical University, and the Department of Anaesthesia, *Tokyo

Women's Medical College

Address correspondence to: Dr. Takashi Matsukawa,

Department of Anaesthesia, Yamanashi Medical University,

Tamaho, Nakakoma, Yamanashi 409-38, Japan.

Phone \& Fax: +81-552-73-6755.

E-mail: takashim@res.yamanashi-med.ac.jp

Accepted for publication July 21, 1996.
Takashi Matsukawa MD, Makoto Ozaki MD,* Kazuyuki Hanagata MD, Hironobu Iwashita MD, Takaharu Miyaji MD, Teruo Kumazawa MD
Conclusion: We conclude that all but the Thermopit ${ }^{\circledR}(T T P)$ are similarly useful for the management of patients during anaesthesia.

Objectif: Comparer les mesures obtenues de quatre thermomètres tympaniques à infra-rouges (Genius ${ }^{\circledR}$, Thermopit ${ }^{\circledR}$, Quickthermo ${ }^{\circledR}$ et Thermoscan $\left.{ }^{\circledR}\right)$ avec celles d'un thermocouple installé dans l'oreille opposée.

Méthodes: Quatre thermomètres tympaniques ont été évalués chez 50 volontaires en bonne santé ( 12 femmes et 38 hommes). Les températures ont été mesurées dans un ordre aléatoire sur la membrane tympanique droite quatre fois. La température la plus élevée a été considérée comme la valeur réelle mesurée par chaque thermomètre. La température de contrôle était mesurée sur la membrane tympanique gauche avec un thermocouple Mon-a-Therm ${ }^{\circledR}$.

Résultats: La température tympanique mesurée par Genius ${ }^{\circledR}$ avait la meilleure corrélation avec la mesure enregistrée par Mon-a-Therm $(T m)(r=0,74)$. Les températures tympaniques mesurées par Thermopit ${ }^{\circledR}$, Quickthermo $^{\circledR}$ et Thermoscan ${ }^{\circledR}$ avaient une corrélation modérée avec $\mathrm{Tm}$ (respectivement $r=56, r=0,63$ et $r=0,58)$. La différence moyenne respective entre $T_{M}$ et chaque température (TG, TTP, TQ et TTS) était de $-0,3,0,73,0,42$ et $-0,3^{\circ} \mathrm{C}$. Dans le même ordre, l'écart type était de 0,33,0,37,0,35 et 0,35.

Conclusion: Tous les thermomètres à l'exception du Thermopit ${ }^{\circledR}$ sont utilisables au même degré pendant l'anesthésie.

Core temperature perturbations are common in the perioperative period ${ }^{1}$ and may indicate underlying problems such as malignant hyperthermia ${ }^{2}$ and inadvertent hypothermia. ${ }^{3}$ Furthermore, thermal disturbances are associated with numerous complication $s^{4-9}$ and should be appropriately treated. ${ }^{10,11}$ Consequently, core temperature monitoring is a critical aspect of anaesthesia practice.

There are various sites for core temperature measurement such as rectal, bladder, oesophageal, and tympanic membrane. ${ }^{12}$ The tympanic membrane shares the same 
vascular supply that perfuses the hypothalamus and is an excellent, readily accessible site $^{13}$ and tympanic membrane temperature is considered to be the most reliable core temperature in clinical practice. ${ }^{14}$

Four infrared tympanic thermometers $\left[\left(\right.\right.$ Genius $^{\circledR}$, Sherwood IMS, Inc., CA, USA), (Thermopit ${ }^{\circledR}$, Nipro, Inc., Osaka, Japan), (Quickthermo ${ }^{\circledR}$, Omron Inc., Mie, Japan), and (Thermoscan ${ }^{\circledR}$, Thermoscan, Inc., CA, USA)] are commercially available in Japan. Each thermometer is a small, battery-operated unit, and consists of an otoscope-like probe (covered by disposable cellophane) that is introduced into the outer third of the auditory canal. The analog output from this sensor is converted to a digital signal for subsequent processing, and the resulting temperature is displayed on a liquid-crystal. ${ }^{15,16}$ To test the hypothesis that these infrared tympanic thermometers are sufficiently accurate and precise for clinical use, we compared measurements made with each thermometer with those recorded from thermocouples positioned in the contralateral ear.

\section{Methods}

The study was approved by the Ethics Committee of the Yamanashi Medical University Hospital. Informed consent was obtained from 50 healthy volunteers (12 female and 38 male). None of the volunteers had a history of problems with the tympanic membrane or middle ear.

Four tympanic thermometers were evaluated: Genius ${ }^{\circledR}$, Thermopit ${ }^{\circledR}$, Quickthermo ${ }^{\circledR}$, and Thermo$\operatorname{scan}^{\circledR}$. With these thermometers, temperatures were measured, in random order generated with a random numbers table, at the right tympanic membrane four times to avoid technical errors, and the highest temperature was considered to be the true value measured by each themometer. The control temperature was measured at the left tympanic membrane using Mon-aTherm ${ }^{\circledR}$ thermocouples (Mallinckrodt Anaesthesiology Products, St. Louis, USA). Visual inspection with an otoscope confirmed that the ear canal was free of wax in each volunteer. The aural probe was inserted by the volunteers until they felt the thermocouple touch the tympanic membrane: appropriate placement was confirmed when volunteers easily detected a gentle rubbing of the attached wire. The aural canal was then occluded with cotton wool, the probe securely taped in place, and a gauze bandage positioned over the external ear.

Correlation coefficient ( $\mathrm{r}$ ), regression analysis, and bias (the mean difference between two methods), were used to compare the agreement of temperature measured by Mon-a-Therm ${ }^{\circledR}$ with each themometer. All values are expressed as mean \pm SD (range).

\section{Results}

The mean height of volunteers was $168 \pm 7$ (153-181) $\mathrm{cm}$, total body mass (TBM) $63 \pm 11(45-90) \mathrm{kg}$, and age $27 \pm 4(22-37) \mathrm{yr}$. The lean body mass (LBM) was $51 \pm$ 7 (39-65) $\mathrm{kg}$ as determined from height $(\mathrm{cm})$ and TBM (kg) using the formula; $\mathrm{LBM}=(1.10 . \mathrm{TBM})-128$ (TBM/height). ${ }^{2,17}$ Basal surface area was $1.8 \pm 0.2$ (1.5-2.1) $\mathrm{m}^{2}$.

The tympanic membrane temperature measured by Genius ${ }^{\circledR}$ (TG) correlated best with the Mon-a-therm ${ }^{\circledR}$ measurement $(\mathrm{TM})(\mathrm{r}=0.74)$. The tympanic membrane temperatures measured by Thermopit ${ }^{\circledR}$ (TTP), Quickthermo ${ }^{\circledR}$ (TQ), and Thermoscan ${ }^{\circledR}$ (TTS) correlated moderately with $T_{M}(r=0.56,0.63$, and 0.58 , respectively) (Figure 1A-1D).

Figure $2 \mathrm{~A}-2 \mathrm{D}$ are plots of the difference between TM and TG, TTP, TQ, or TTS using the Bland-Altman method of analysis. Regression coefficient and the slope of the regression plot with TM and TG, TTP, TQ, and TTS were $(0.74,0.90),(0.56,0.67),(0.63,0.79)$ and $(0.58,0.65)$, respectively. The slope of the regression for the Genius ${ }^{\circledR}$ thermometer was significantly closer to one than with the other three infrared instruments. Mean differences between $\mathrm{TM}$ and each temperature (TG, TTP, $\mathrm{TQ}$, and TTs) were $-0.34,0.73,0.42$, and $-0.30^{\circ} \mathrm{C}$, respectively. Likewise standard deviations were 0.33 , $0.37,0.35$, and 0.35 (Table).

\section{Discussion}

Four infrared tympanic thermometers were evaluated in the present study. Each is now commercially available in Japan, but no study has tested which is the most accurate and precise for routine use. Our data demonstrated that, in general, all but the Thermopit ${ }^{\circledR}$ (TTP) were similarly useful for the anaesthetic management of the patients.

Several factors may affect the measurement of tympanic membrane temperature. The shape of the ear canal probe is one of the most important for accurate measurement. In additon, each thermometer has its own unique mechanism in which analog output from the sensor is converted to a digital signal for subsequent processing. ${ }^{15,16}$ Therefore, both the shape of the ear canal and original mechanism may be the factors causing variation between the thermometer and thermocouple.

The purpose of this study was to validate the accuracy of specific infrared tympanic thermometers during anaesthesia for minor surgical procedure. In such cases the duration of anaesthesia is normally less than two hours and there is reluctance to use the disposable thermocouples or thermister probes because they cost at least US\$10 and the variation range of core temperature is not wide. Accordingly, continuous monitoring of tem- 

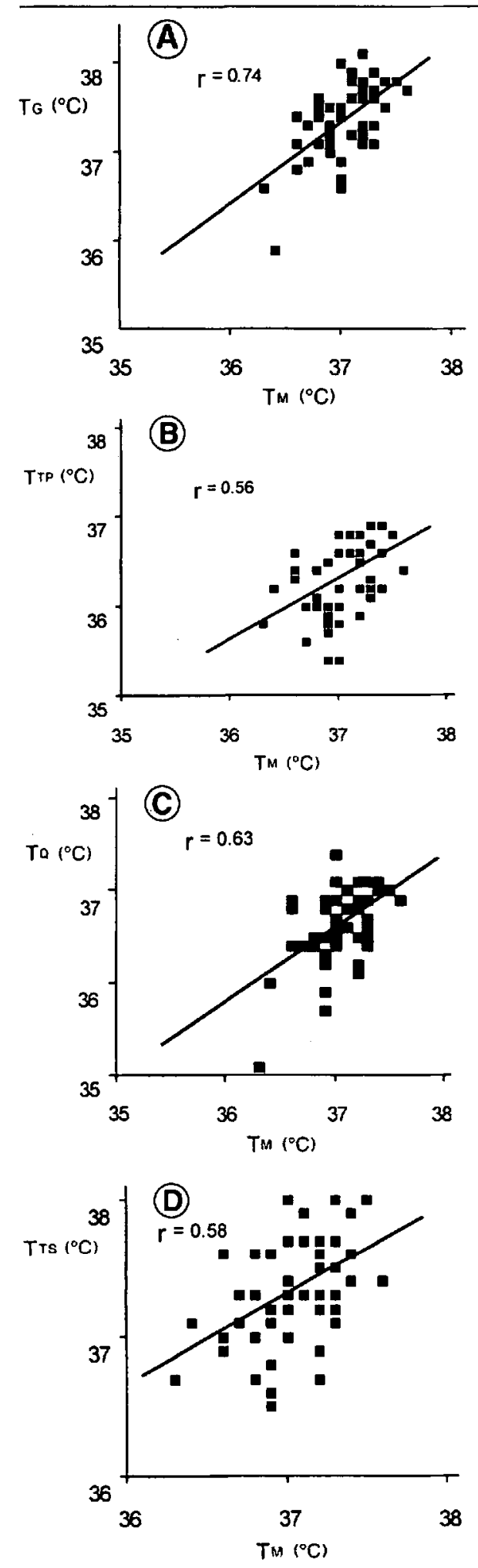

FIGURE 1 Relationship between the Mon-a-Therm ${ }^{\circledR}$ measurement (TM) and the tympanic membrane temperature measured by (A) Genius $^{(1)}(\mathrm{TG})(r=0.74)$, (B) Thermopit ${ }^{\circledR}$ (TTP) $(r=0.56)$, (C) Quickthermo ${ }^{\circledR}(\mathrm{TQ})(r=0.63)$, and (D) Thermoscan ${ }^{\circledR}(\mathrm{TTS})(r=$ 0.58 ). To correlated best with TM.
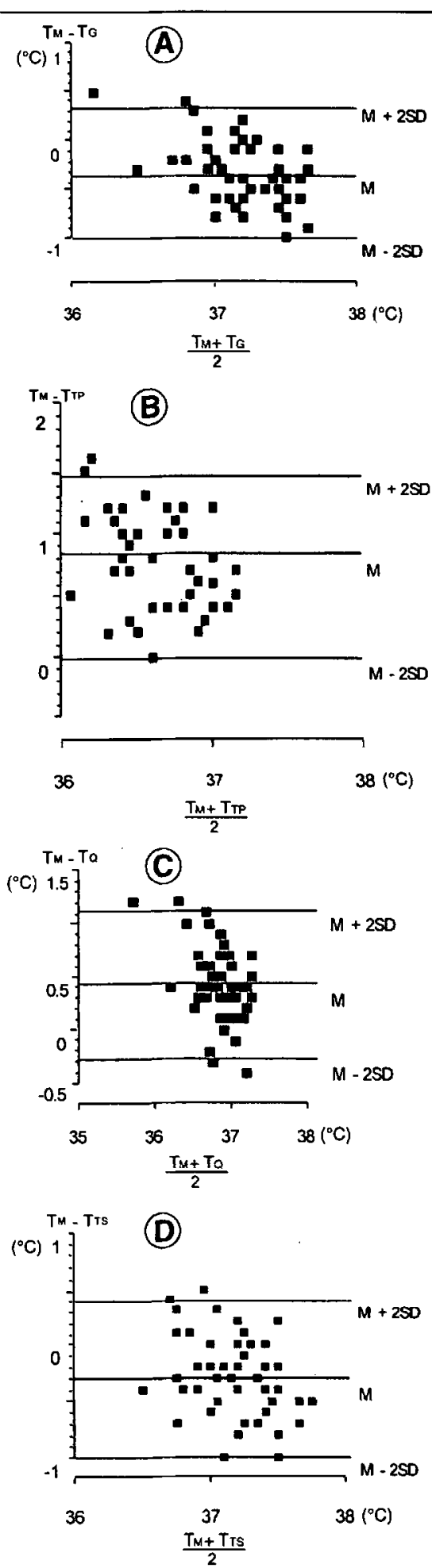

FIGURE 2 The differences between the Mon-a-Therm ${ }^{\circledR}$ measurement (TM) and the tympanic membrane temperature measured by $(A)$ Genius $^{(B)}$ (TG), (B) Thermopit $\left.{ }^{(}\right)$(TTP), (C) Quickthermo ${ }^{\circledR}(\mathrm{TQ})$, and (D) Thermoscan ${ }^{(\mathcal{B}}$ (TTS), against the average temperature. Mean differences between $\mathrm{TM}$ and each temperature ( $\mathrm{TG}, \mathrm{TTP}, \mathrm{TQ}$, and $\mathrm{TTS}$ ) were $-0.3,0.73,0.42$, and $-0.3^{\circ} \mathrm{C}$, respectively. $\mathrm{M}$ : mean, SD: standard deviation. 
TABLE Limits of agreement of thermocouple and thermometer measurements by Bland and Altman analysis ${ }^{20,21}$

\begin{tabular}{lrrrr}
\hline & \multicolumn{1}{c}{$T_{G}$} & $T_{T P}$ & \multicolumn{1}{c}{$T_{Q}$} & \multicolumn{1}{c}{$T_{T S}$} \\
\hline $\mathrm{r}$ & 0.74 & 0.56 & 0.63 & 0.58 \\
Slope & 0.90 & 0.67 & 0.79 & 0.65 \\
& & & & \\
Agreement $\left({ }^{\circ} \mathrm{C}\right)$ & & & & \\
Mean & -0.34 & 0.73 & 0.42 & -0.30 \\
SD & 0.33 & 0.37 & 0.35 & 0.35 \\
Mean + 2SD & 0.32 & 1.47 & 1.12 & 0.40 \\
Mean - 2SD & -1.00 & -0.01 & -0.28 & -1.00 \\
\hline
\end{tabular}

TM: Thermocouple (Mon-a-Therm@) measurement. TG: Tympanic membrane temperature measured by Genius( 1 . TTP: Tympanic membrane temperature measured by Thermopit $\circledast$. TQ: Tympanic membrane temperature measured by Quickthermo®. Trs: Tympanic membrane temperature measured by Thermoscan $B$.

perature is less acceptable than during major surgery like cardiac, vascular, or open chest surgery. Although our tested range was very limited due to the use of volunteers, we can still apply our results to the clinical situation because the range of core temperature change in surgery lasting less than two hours is similar.

There are two temperatures relevant to thermoregulation: central, reflecting body core temperature, and peripheral, reflecting the temperature of the body shell and environment. ${ }^{18}$ Physiological thermoregulation is a complex interaction between core and shell. In an unanaesthetized human core temperature is maintained within $0.2^{\circ} \mathrm{C}$ of normal. However, anaesthesia and surgery remarkably alter the body temperature. ${ }^{19}$

Temperature measurement is a time-honoured practice. A variety of devices, including glass-mercury thermometers, liquid crystal thermometers, rectal thermistors, urinary catheter thermistors, pulmonary artery catheter thermistors, and tympanic membrane thermistors have been used to measure core temperature, intermittently or continuously. An optimal thermometer should accurately measure core temperature. ${ }^{19}$

The tympanic membrane is an excellent site for measurement of core temperature, since it is readily accessible and receives its blood supply from a portion of the same vasculature that perfuses the hypothalamus. ${ }^{14}$ Tympanic membrane thermocouple probes are safe and relatively easy to use. Nonetheless, they must be inserted carefully and some patients find them uncomfortable during regional anaesthesia. An alternative to a fixed probe is intermittent aural canal temperature measurements using an infrared thermometer. ${ }^{15,16}$

In summary, four infrared tympanic thermometers (Genius $^{\circledR}$, Thermopit ${ }^{\circledR}$, Quickthermo ${ }^{\circledR}$, and Thermoscan $^{(\mathbb{B})}$ ), commercially available in Japan, were evaluated. We conclude that, in general, all but the Thermopit ${ }^{\circledR}$
(TTP) were similarly useful for the management of patients during anaesthesia.

\section{Acknowledgment}

We would like to thank Sherwood IMS, Inc. for the loan of the thermometers and for donation of the thermocouples.

\section{References}

1 Vaughan RW, Vaughan MS. Temperature: our most neglected perioperative monitor. Seminars in Anesthesia 1988; VII: 38-46.

2 Sessler DI. Malignant hyperthermia. J Pediatr 1986; 109: 9-14.

3 Morris $R H$. Operating room temperature and the anesthetized, paralyzed patient. Arch Surg 1971; 102: 95-7.

4 Sessler DI, Rubinstein EH, Moayeri A. Physiologic responses to mild perianesthetic hypothermia in humans. Anesthesiology 1991; 75: 594-610.

5 Heier T, Caldwell JE, Sessler DI, Miller RD. Mild intraoperative hypothermia increases duration of action and spontaneous recovery of vecuronium blockade during nitrous oxide-isoflurane anesthesia in humans. Anesthesiology 1991; 74: 815-9.

6 Leslie K, Sessler DI, Bjorksten AR, Moayeri A. Mild hypothermia prolongs the duration of action of atracurium. Anesthesiology 1993; 79: A930.

7 Frank SM, Beattie C, Christopherson R, et al. Unintentional hypothermia is associated with postoperative myocardial ischemia. Anesthesiology 1993; 78: 468-76.

8 Valeri CR, Feingold H, Cassidy G, Ragno G, Khuri S, Altschule MD. Hypothermia-induced reversible platelet dysfunction. Ann Surg 1987; 205: 175-81.

9 Carli F, Emery $P W$, Freemantle CAJ. Effect of peroperative normothermia on postoperative protein metabolism in elderly patients undergoing hip arthroplasty. $\mathrm{Br} \mathrm{J}$ Anaesth 1989; 63: 276-82.

10 Hynson JM, Sessler DI. Intraoperative warming therapies; a comparison of three devices. J Clin Anesth 1992; 4: 194-9.

11 Kurz A, Kurz M, Poeschl G, Faryniak B, Redl G, Hackl W. Forced-air warming maintains intraoperative normothermia better than circulating-water mattresses. Anesth Analg 1993; 77: 89-95.

12 Cork RC, Vaughan RW, Humphrey LS. Precision and accuracy of intraoperative temperature monitoring. Anesth Analg 1983; 62: 211-4.

13 Benzinger $T H$. Clinical temperature. New physiological basis. JAMA 1969; 209: 1200-6.

14 Benzinger $M$. Tympanic thermometry in surgery and anesthesia. JAMA 1969; 209: 1207-11.

15 Matsukawa T, Kashimoto S, Miyaji T, Hanagata K, Iriki 
$M$, Kumazawa $T$. A new infrared tympanic thermometer in surgery and anesthesia. J Anesth 1993; 7: 33-9.

16 Shinozaki T, Deane R, Perkins FM. Infrared tympanic thermometer: evaluation of a new clinical thermometer. Crit Care Med 1988; 16: 148-50.

17 Leslie K, Sessler DI, Bjorksten AR, et al. Propofol causes a dose-dependent decrease in the thermoregulatory threshold for vasoconstriction but has little effect on sweating. Anesthesiology 1994; 81: 353-60.

18 Imrie MM, Hall GM. Body temperature and anaesthesia. Br J Anaesth 1990; 64: 346-54.

19 Sato KT, Kane NL, Soos G, Gisolfi CV, Kondo N, Sato K. Reexamination of tympanic membrane temperature as a core temperature. J Appl Physiol 1996; 80: 1233-9.

20 Bland JM, Altman DG. Statistical methods for assessing agreement between two methods of clinical measurement. Lancet 1986; 1: 307-10.

21 Altman DG, Bland JM. Measurement in medicine: the analysis of method comparison studies. Statistician 1983; 32: 307-17. 